\title{
Short term electrical load forecasting using holt-winters method
}

\author{
Dr. Majed Saleh Al-Hafid Ghazi Hussein Al-maamary \\ Department of Electrical Engineering-Mosul University / Mosul - Iraq
}

\begin{abstract}
Load forecasting is a process of predicting the future load demands. It is important for electrical power system planners and demand controllers in ensuring that there would be enough supply of electricity to cope with increasing demands. Thus, accurate load forecasting can lead to an overall reduction of cost, better budget planning, maintenance scheduling and fuel management. Therefore this study aimed to develop new forecasting model for forecasting electricity load demand which will minimize the error of forecasting. This paper presents an attempt to forecast the daily peak demand of electricity by using an appropriate time series model. It is the Seasonal Holt-Winters method. The performance of this method was evaluated by using the forecasting accuracy criteria namely, the Absolute Percentage Error (APE) and the Mean Absolute Percentage Error (MAPE). Based on these criteria the Holt-Winters method emerged as a suitable model for forecasting electricity demand in Iraq.

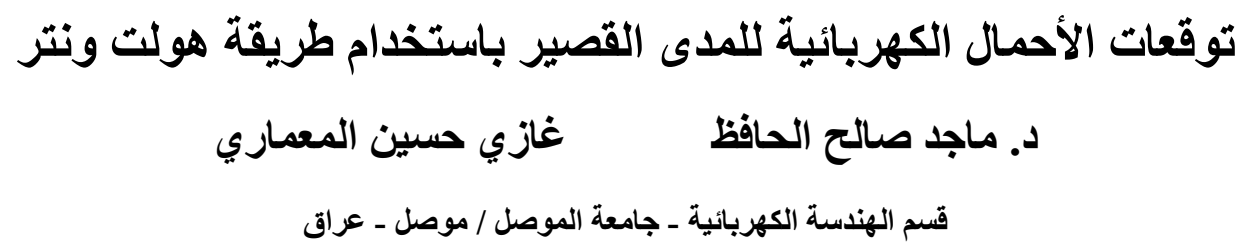

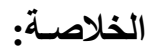

توقعات الأحمال هي عملية تخمين الأحمال المستقبلية, وهي مهمـة بالنسبة لمخططي نظام القدرة والمسيطرين

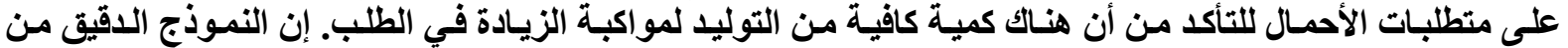

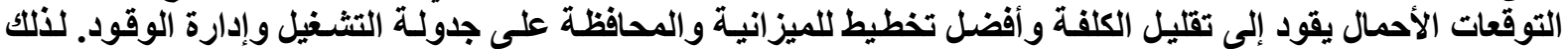

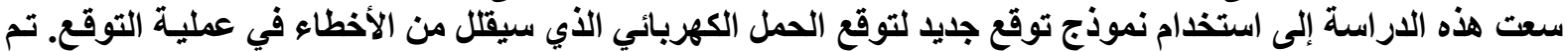

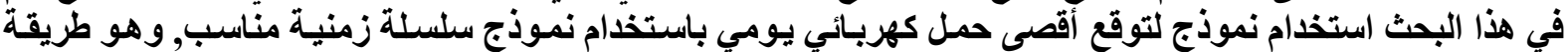

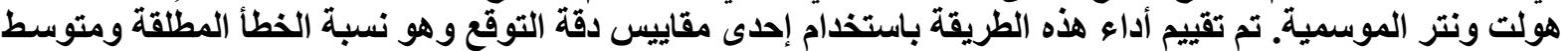

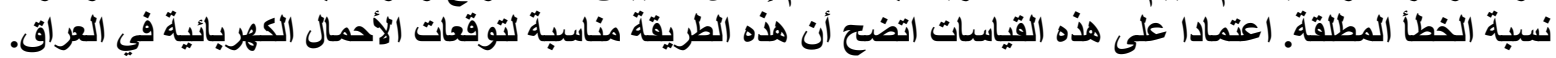




\section{Introduction:}

Forecasting demand is an essential activity and is one of the most important functions in power system planning and development. It is a prerequisite to power system expansion planning as the electrical installations (Generating station, transmission line, distribution system ... etc.) are dominated by substantial lead times between decision making and its implementation. This is further complicated because the product i.e., electricity cannot be stored (in large volume) and also, the electricity supply industry is capital intensive. The importance of demand forecasting needs to be emphasized at all level as the consequences of under or over forecasting. The accurate demand forecasting is serious and will affect all stakeholders in the electricity supply industry. If under estimated, the result is serious since plant installation cannot easily be advanced, this will affect the economy, business, loss of time and image. If overestimated, the financial penalty for excess capacity (i.e., overestimated and wasting of resources) [1].

Load forecasts can be divided into three categories: short term (STLF), medium term (MTLF), and long-term forecasts (LTLF). STLF, which is usually from one hour to one week, is concerned with forecast of hourly and daily peak system load, and daily or weekly system energy. It is needed for controlling and scheduling of power system, and also as inputs to Load flow study or contingency analysis. Some of the techniques used for STLF are multiple linear regression, stochastic time series and artificial intelligence based approach. MTLF relates to a time frame from a week to a year and LTLF relates to more than a year. MTLF and LTLF are required for maintenance scheduling, fuel and hydro planning, and generation and transmission expansion planning. The common techniques used for MTLF and LTLF are time trend extrapolation and econometric multiple regression $[2,3]$.

The electrical load in many countries includes two components, one of them is not affected by weather andthe other is affected by weather (either by increasing or decreasing of temperturedegrees). While in Iraq the component that affected by weather is affected by both increasing and decreasing of temperture degrees. In the past and exactly in the seventieth and eithieth decadesof the previous centurythe summer component was dominant peak load, but fromabout 2002 the winter component appears and became more than summer component, because of the increasing use of water heating, heaters, air conditioner and splits[5].

In 2006 (F. Abd. Razak, M. Shitan, A. H. Hashim, I. Z. Abidin) presented an attempt to forecast the maximum demand of electricity in Malaysia by finding an appropriate time series model. The methods considered in this study include the Naïve method, Exponential smoothing, Holt's linear method, Seasonal Holt-Winters, ARMA and ARAR algorithm. The performance of these different methods was evaluated by using the forecasting accuracy criteria namely, the Mean Absolute Error (MAE), Root Mean Square Error (RMSE) and Mean Absolute Percentage Error (MAPE). Based on these three criteria the pure autoregressive model with an order 2, or AR (2) emerged as the best model for forecasting [3].

In September (2006), the General Management for North Region Electrical Distribution in Iraq presented the long term plan for feeding sources $(33,132) \mathrm{KV}$ for years $(2005-2020)$. The study performed for north conservatisms (Nineveh, Selah Alden, and Kirkuk). They computed the demands for 2005 and then they predicted to other years until 2025. The load have been computed depending on these methods [6]:

- Consider average of growth 5\% for period 1990-2005. 
- Consider the load by summing the loads of the stations that worked now and then they multiplied by suitable diversity factor.

- Analyzing the daily load curve for the actual supplied energy for conservatisms, that presented by the north control center.

But the actual loads at year 2010 exceed what was expected in the study at 2010, and at year2011 the actual loads exceed what was expected in 2015.

In this paper, a holt-winters method is used for forecasting the daily peak load data. This method is appropriate to be applied to Iraqi data.

\section{The data:}

The data used in this study is the daily peak load. The loads are recorded at daily intervals. The total observations are 820, started from Thursday, 1-January, 2009 to Thursday, 31-March, 2011. These data are provided by the General Management for North Region Electrical Distribution in Iraq. The data show a periodic repetition, due to weather changes. The time series of demand contains one seasonal pattern. A yearly seasonal cycle is apparent from the similarity of the demand profile from one year to the next year.

\section{The forecast accuracy:}

The criteria chosen to measure the accuracy of the forecasted data in this study are the Absolute Percentage Error (APE) and the Mean Absolute Percentage Error (MAPE), which are given by the following equations:

$\mathrm{APE}=\left|\frac{\mathrm{Y}_{\mathrm{t}}-\mathrm{F}_{\mathrm{t}}}{\mathrm{Y}_{\mathrm{t}}}\right| * 100 \%$

MAPE $=\frac{\sum_{1}^{\mathrm{n}}\left|\frac{\mathrm{Y}_{\mathrm{t}}-\mathrm{F}_{\mathrm{t}}}{\mathrm{Y}_{\mathrm{t}}}\right|}{\mathrm{n}} * 100 \%$

Where $Y_{t}$ and $F_{t}$ are the actual observed values of electrical loads and the predicted values respectively, while $n$ is the number of predicted values [3].

\section{Holt-Winter method:}

\section{A. Theory:}

The standard Holt-Winters method was introduced by Winters. The Winter's method is one of several exponential smoothing methods which can analyze seasonal time series directly. The method is based on three smoothing equations-one for the level (permanent), one for trend, and one for seasonality (seasonal factor), and it can be either additive or multiplicative seasonality. The multiplicative seasonality is appropriate if the magnitude of the seasonal variation increases with an increase in the mean level of the series. Multiplicative seasonality is considered in this paper since it is more common, and suitable for our data. The Three components (Level, trend, and seasonal) are calculated according to the following equations. The basic equations are[2,3]:

$$
\begin{aligned}
& \text { Level: } \mathrm{L}_{\mathrm{t}}=\alpha \frac{\mathrm{Y}_{\mathrm{t}}}{\mathrm{S}_{\mathrm{t}-\mathrm{s}}}+(1-\alpha)\left(\mathrm{L}_{\mathrm{t}-1}+\mathrm{m}_{\mathrm{t}-1}\right) \\
& \text { Trend: } \mathrm{m}_{\mathrm{t}}=\beta\left(\mathrm{L}_{\mathrm{t}}-\mathrm{L}_{\mathrm{t}-1}\right)+(1-\beta) \mathrm{m}_{\mathrm{t}-1} \\
& \text { Seasonal: } \mathrm{S}_{\mathrm{t}}(\mathrm{t})=\gamma \frac{\mathrm{Y}_{\mathrm{t}}}{\mathrm{L}_{\mathrm{t}}}+(1-\gamma) \mathrm{S}_{\mathrm{t}-\mathrm{s}}(\mathrm{t})
\end{aligned}
$$


Forecast: $F_{t+\tau}=\left(L_{t}+m_{t} q\right) S_{t-s+\tau}$

Where:

$\alpha, \beta$ and $\gamma$ are smoothing constants.

$\mathrm{t}$ is the time period.

$Y_{t}$ is the actual observed values.

$s$ is the length of seasonality.

$\mathrm{L}_{\mathrm{t}}$ is the level component.

$\mathrm{m}_{\mathrm{t}}$ is the trend component.

$\mathrm{S}_{\mathrm{t}}$ is the seasonal component.

$\mathrm{F}_{\mathrm{t}+\tau}$ is the forecast for $\tau$ periods ahead.

The forecasted load is calculated using equation 6. It contains three components (level, trend, and seasonal). These components are calculated using equations 3, 4 and 5; each component has certain smoothing constant $(\alpha, \beta$ and $\gamma)$. To find the best time series model which fits the load data (with minimum error) these smoothing constants are found, which are called optimal smoothing constants. This time series model is ready now to forecast future loads.

The flow chart that describes this method is illustrated in figure(1).The development of a forecasting system using Winter's method requires initial values of the parameters $\mathrm{L}_{0}, \mathrm{~m}_{0}$ and $\mathrm{S}_{\mathrm{t}}(0)$ for $\mathrm{t}=1,2, \ldots \mathrm{s}$. Historical information, if available, can be used to provide some or all of the initial values. The estimate of the trend component can be found by:

$$
m_{0}=\frac{x_{d}-x_{1}}{(d-1) * s}
$$

Where: $\mathrm{d}$ is the number of seasons which are used to determine the initial values and $\mathrm{x}_{r}, r=1$, $2 \ldots \mathrm{d}$, denote the average of the observations during the $r$ th season.

The permanent component at the start of the first period would be estimated by:

$L_{0}=x_{1}$

Seasonal factors are computed for each time period $t=1,2 \ldots . d * s$. that is:

$c h_{t}=\frac{x_{t}}{x_{i}-[(s+1) / 2-j] m_{0}} \quad \mathrm{t}=1,2 \ldots \mathrm{d}^{*} \mathrm{~s}$.

Where: $x_{i}$ is the average for a season corresponding to the $t$ index, and $\mathrm{j}$ is the position of the period $\mathrm{t}$ within the season (for example, if $1 \leq \mathrm{t} \leq \mathrm{s}$, then $\mathrm{i}=1$, and if $\mathrm{s}+1 \leq \mathrm{t} \leq 2 \mathrm{~s}$, then $\mathrm{i}=2$; and when $t=1$ and $t=s+1$, then $j=1$, etc.). Equation (7) will produce $d$ estimates of the seasonal factor for each period. These should be averaged to produce a single estimate of the seasonal factor for each period within the season. This is accomplished by:

$c x_{t}=\frac{1}{d} \sum_{k=0}^{d-1} c h_{t+k s} \quad \mathrm{t}=1,2 \ldots \mathrm{s}$.

Finally, the seasonal factors should be normalized so that they add to s. This produces the initial estimates of the seasonal factors as [4]:

$S_{t}(0)=c x_{t} \frac{s}{\sum_{t=1}^{s} c x_{t}} \quad \mathrm{t}=1,2 \ldots \mathrm{s}$. 


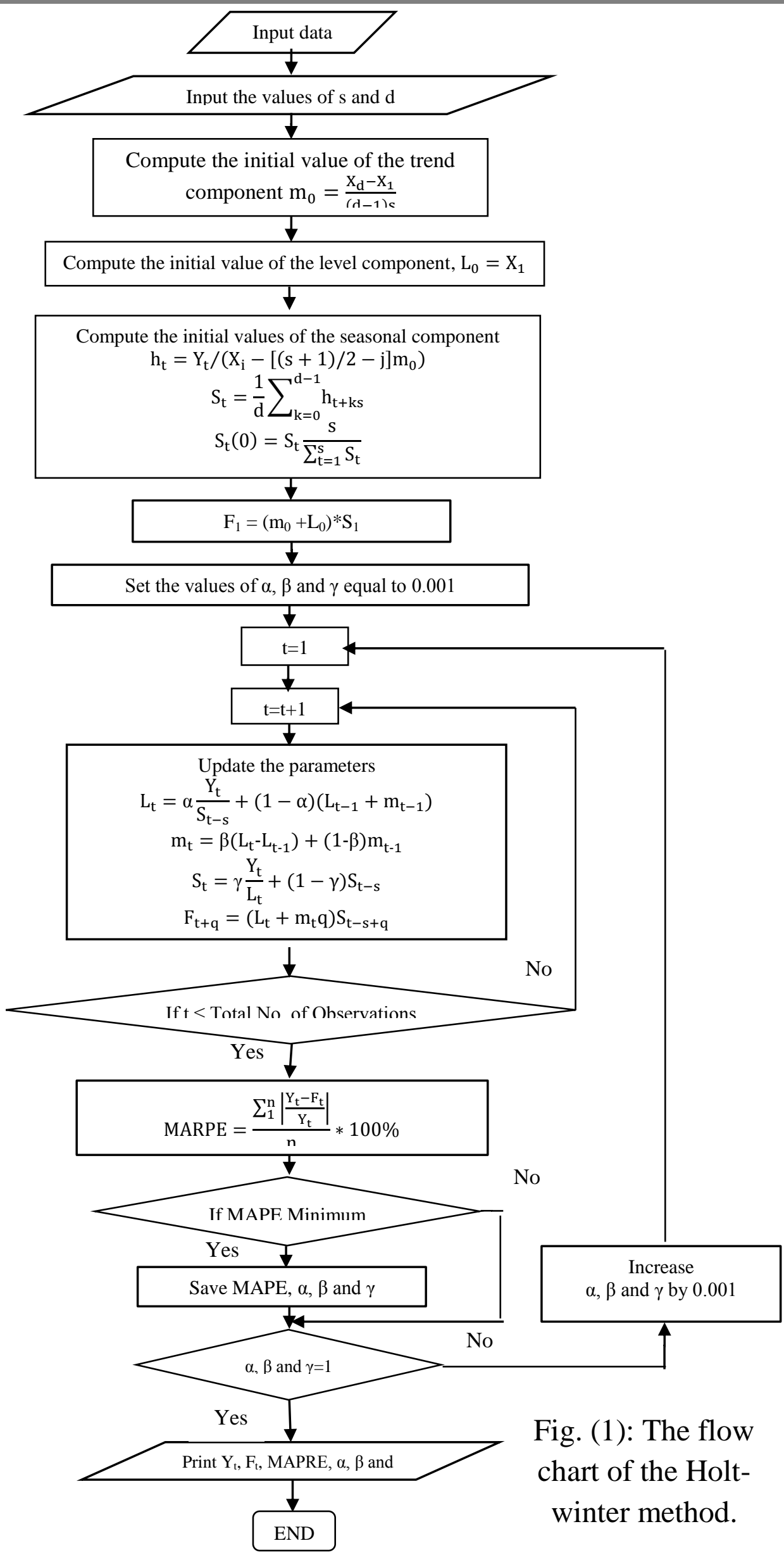




\section{B. Implementation:}

The holt-winter method is applied on the daily peak load data that are recorded in Mosul city by the General Management for North Region Electrical Distribution to forecast it. The forecasting method is programmed by the Mat lab program in PC. The data are divided two parts, the first part contains 813observations which are used to find the initial values of the parameters $\mathrm{L}_{0}, \mathrm{~m}_{0}$ and $\mathrm{S}_{\mathrm{t}}(0)$ for $\mathrm{t}=1,2, \ldots \mathrm{s}$. Where $\mathrm{s}=365$ and $\mathrm{d}=2, \mathrm{~s}^{*} \mathrm{~d}$ must be more than half the data used to find the initial values of the parameters, and then the equations $(3-6)$ are implemented to forecast one step ahead at $\tau=1$. And the second part of the data is used to test the forecast by forecasting to seven steps ahead and comparing the actual values with that forecasted, where $\tau=2,3,4,5,6,7,8$.

\section{Results and discussion:}

The first results are the values of the smoothing constants and MAPE for one step ahead forecasting are illustrated in Tableland the actual and forecasted load curves are illustrated in figure (2). The MAPE is $3.94 \%$. The second results are load forecasted for seven steps ahead. Table (2) gives the actual and forecasted load values with APE for each step. The actual and forecasted loads are plotted in figure3. The MAPE for this case is 4.49 $\%$.

There were some differences between the actual load values and the forecasted load values because the actual data observations are implemented directly without preprocess. Original data usually contain abnormal values (noise), so they need to be processed before using them in predicting electrical load. Wavelet or statistical methods are usually introduced for such preprocessing of data. The processed data will give better accuracy. To extend the forecasted period more past data are needed.

Table 1. Smoothing constants and MAPE.

\begin{tabular}{|c|c|c|c|}
\hline$\alpha$ & $\beta$ & $\gamma$ & MAPE\% \\
\hline 0.24 & $1.0 \mathrm{e}-5$ & $1.0 \mathrm{e}-5$ & 3.948 \\
\hline
\end{tabular}

Table 2.The actual and forecasted values and APE for seven steps ahead.

\begin{tabular}{|c|c|c|c|}
\hline \multirow{2}{*}{ Days $(\tau)$} & \multicolumn{2}{|c|}{ Observations } & \multirow{2}{*}{ APE\% } \\
\cline { 2 - 3 } & Actual & Forecast & \\
\hline 2 & 605 & 655.905 & 8.414 \\
\hline 3 & 613 & 602.588 & 1.699 \\
\hline 4 & 620 & 595.559 & 3.942 \\
\hline 5 & 671 & 674.475 & 0.518 \\
\hline 6 & 630 & 687.966 & 9.201 \\
\hline 7 & 612 & 640.739 & 4.696 \\
\hline 8 & 606 & 623.939 & 2.960 \\
\hline
\end{tabular}

\section{Conclusion:}

This paper presents an attempt to forecast the daily peak demand of electricity by using an appropriate time series model. It is a Holt-Winter model. The results of the MAPE indicated for one step ahead is $3.94 \%$, and for seven steps ahead is $4.49 \%$. Therefore, Holt- 
Winter multiplicative seasonal model can be used to forecast loads even for unstable or weak electrical systems.

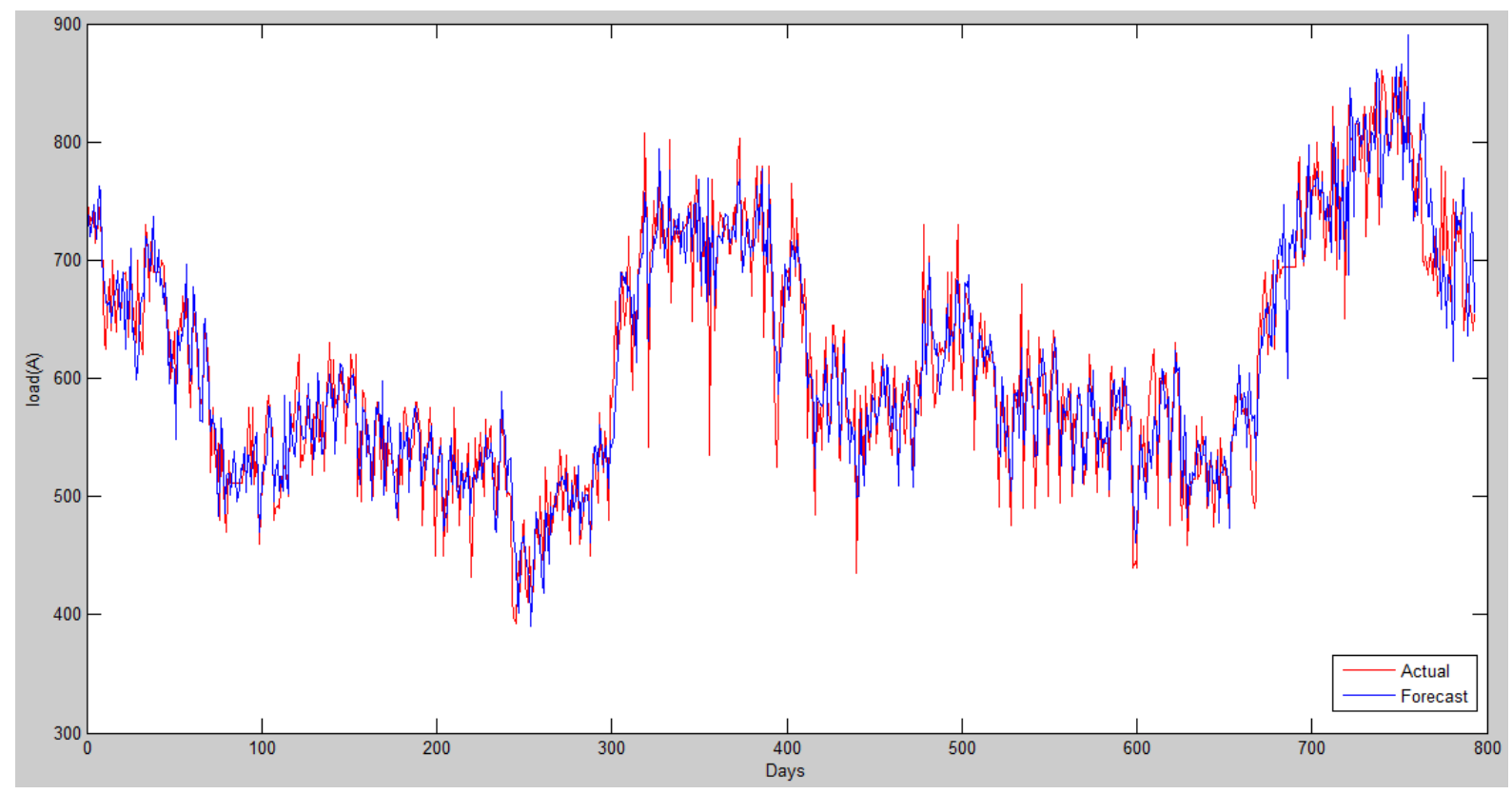

Fig. (2): The actual and predicted loads curves for one step ahead forecasting at $\tau=1$.

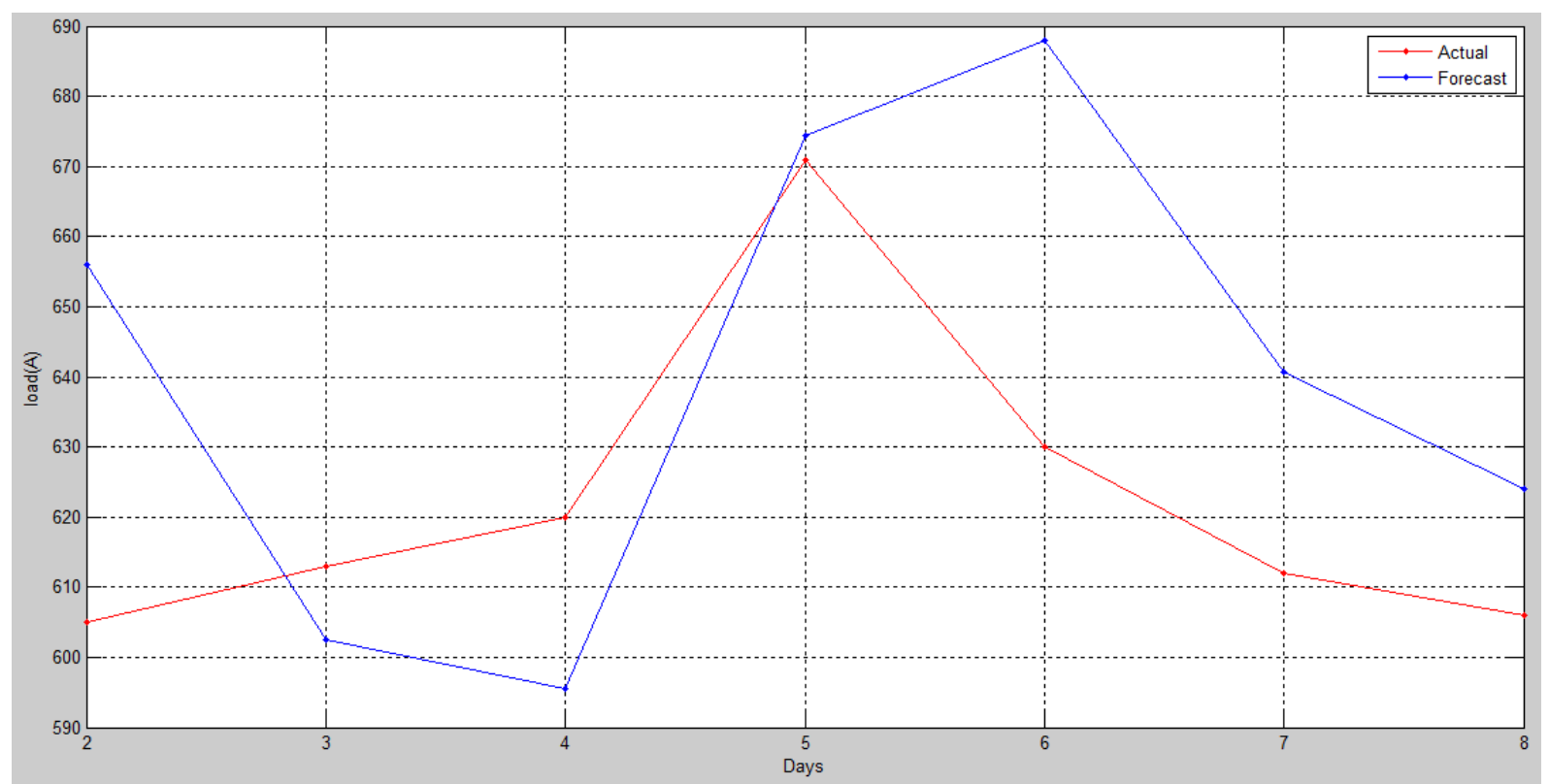

Fig. (3): The actual and predicted loads curves for forecasting seven steps ahead. 


\section{ACKNOWLEDGMENT}

The researchers express their deep gratitude and thanks to the administration and the engineers of the General Management for North Region Electrical Distribution for their valuable help and cooperation in this study.

\section{References}

[1] Z. Ismail, A.Yahya and K.A. Mahpol, "Forecasting Peak Load Electricity Demand Using Statistics and Rule Based Approach", American Journal of Applied Sciences 6 (8): 1618-1625, 2009.

[2] James W. Taylor "Short-Term Electricity Demand Forecasting Using Double Seasonal Exponential Smoothing" University of Oxford, Journal of Operational Research Society, 2003, Vol. 54, pp. 799-805.

[3] Fadhilah Abd. Razak, Mahendran Shitan, Amir .H. Hashim, Izham. Z. Abidin "Forecasting the Maximum Demand of Electricity in Malaysia" International Conference on Energy and Environment 2006 (ICEE 2006).

[4] Douglas C. Montgomery and Lynwood A. Johnson "Forecasting and Time Series Analysis", McGraw-Hill, Inc, 1976. (Book)

[5] M. S. Al-Hafid, A. S. Al-Fahadi and Y. A. Mahmood "Separation of The components of Electrical Load for the Iraqi Distribution System" Fifth Libyan Arab International Conference On Electrical and electronic Engineering,Vol.2,October23-26,2010.

[6] The General Management for North Region Electrical Distribution, "The long term plan for feeding sources $(33,132) \mathrm{KV}$ for years (2005-2020)" September (2006). 